\title{
Médiévales
}

Langues, Textes, Histoire

48 | printemps 2005

Princes et princesses à la fin du Moyen Âge

\section{Stephani de Borbone [Étienne de Bourbon], Tractatus de diversis materiis predicabilibus, Prologus, Prima Pars. De Dono timoris / Humbert de Romans, Le Don de crainte ou l'Abondance des exemples}

Éd. Jacques Berlioz et Jean-Luc Eichenlaub, Turnhout, Brepols, 2002 (Corpus Christianorum, Continuatio Mediaevalis, CXXIV), xcii+638 p. / Traduit du latin et présenté par Christine Boyer, Postface de Jacques Berlioz, Lyon, PUL, 2003, 242 p.

Christopher Lucken

\section{(2) OpenEdition}

Édition électronique

URL : https://journals.openedition.org/medievales/1089

DOI : 10.4000/medievales. 1089

ISSN : 1777-5892

Éditeur

Presses universitaires de Vincennes

Édition imprimée

Date de publication : 1 juin 2005

Pagination : 170-173

ISBN : 2-84292-169-0

ISSN : 0751-2708

Référence électronique

Christopher Lucken, «Stephani de Borbone [Étienne de Bourbon], Tractatus de diversis materiis predicabilibus, Prologus, Prima Pars. De Dono timoris / Humbert de Romans, Le Don de crainte ou l'Abondance des exemples », Médiévales [En ligne], 48 I printemps 2005, mis en ligne le 08 décembre 2005, consulté le 23 avril 2022. URL : http://journals.openedition.org/medievales/1089 ; DOI : https:// doi.org/10.4000/medievales. 1089

Ce document a été généré automatiquement le 23 avril 2022.

Tous droits réservés 


\section{Stephani de Borbone [Étienne de Bourbon], Tractatus de diversis} materiis predicabilibus, Prologus, Prima Pars. De Dono timoris / Humbert de Romans, Le Don de crainte ou l'Abondance des exemples

Éd. Jacques Berlioz et Jean-Luc Eichenlaub, Turnhout, Brepols, 2002 (Corpus Christianorum, Continuatio Mediaevalis, CXXIV), xcii+638 p. / Traduit du latin et présenté par Christine Boyer, Postface de Jacques Berlioz, Lyon, PUL, 2003, 242 p.

\section{Christopher Lucken}

Saluons pour commencer la parution du premier tome de la collection des Exempla Medii Aevi dirigée par J. Berlioz, M. A. Polo de Beaulieu et J.-Cl. Schmitt dans la série Continuatio Mediaevalis de la célèbre collection du Corpus Christianorum publiée aux éditions Brepols! Objets principalement des études folkloristes depuis la fin du xIx siècle, les exempla médiévaux ont suscité en France, à la fin des années 1960, l'intérêt d'un certain nombre d'historiens « des mentalités » réunis autour de J. Le Goff dans le cadre du séminaire de recherche que celui-ci dirigeait à l'EHESS et qui était consacré aux rapports entre la culture savante et la culture populaire dans l'Occident médiéval. Jusque-là, les exempla avaient intéressé principalement les folkloristes, qui les avaient enfermés le plus souvent au sein d'une tradition « populaire » qui semblait indifférente au contexte historique dans lequel ces textes étaient produits et aux objectifs spécifiques qui avaient pu présider à leur existence; ils avaient alors fait l'objet d'un classement, établi par F. C. Tubach dans son célèbre Index Exemplorum, destiné à les regrouper en un certain nombre de récits types et à en permettre l'identification ${ }^{1}$. Pour les historiens, en revanche, les exempla apparaissaient comme une source privilégiée 
permettant une connaissance plus précise de la culture populaire et des mentalités au sein de la société médiévale (dont on avait étudié jusque là, principalement, les institutions et la culture savante). Ils suscitaient du même coup des recherches consacrées aux nombreuses entreprises de prédication qui se manifestèrent au cours $\mathrm{du} \mathrm{XII}^{\mathrm{e}}$ siècle et qui se sont intensifiées aux siècles suivants avec l'apparition et l'expansion des ordres mendiants ${ }^{2}$. Faisaient notamment partie de ce groupe, J.Cl. Schmitt (dont les études qu'il a menées depuis sur le folklore et sur le rôle des images dans la culture chrétienne entretiennent d'importants liens avec les recherches consacrées aux exempla) et $\mathrm{Cl}$. Bremond (dont les travaux sur La logique du récit devaient permettre de dégager les principales fonctions narratives dont son constitués les différents récits étudiés). En 1982, ces deux chercheurs firent paraître avec J. Le Goff, dans la série Typologie des sources du moyen âge occidental, un important fascicule consacré à L'Exemplum ${ }^{3}$. Depuis, les travaux se sont multipliés. Il existe désormais, dans le prolongement des activités menées dans le cadre du séminaire de J. Le Goff, un "Groupe de recherche sur les exempla médiévaux» (qui fait partie du Groupe d'Anthroplogie Historique de l'Occident Médiéval fondé par J. Le Goff et dirigé actuellement par J.-Cl. Schmitt). Ce Groupe de Recherche est animé principalement par J. Berlioz et A. M. Polo de Beaulieu. Il s'est donné trois activités principales : l'édition des recueils d'exempla les plus importants (c'est à quoi est consacrée la collection des Exempla Medii Aevi dont il est ici question), la constitution d'un Thesaurus Exemplorum Medii Aevi destiné à faciliter le repérage des différents récits que l'on peut associer à cette tradition littéraire et de leurs variantes (avec la création d'une base de donnée accessible sur Internet: http://www.ehess.fr/gahom/ThesEx.htm), et l'étude de cette production narrative et de son environnement historique et textuel (avec la constitution d'une Bibliographie européenne des exempla, la Bibliex, elle aussi accessible sur Internet : http://www.ehess.fr/gahom/Bibliex.htm). La plupart des travaux menés aujourd'hui sur les exempla au Moyen Âge et la quasi totalité de ce qui se fait en France s'inscrit dans ce cadre ${ }^{4}$.

2 Il n'est guère surprenant que le nom d'Étienne de Bourbon figure en tête de la collection des Exempla Medii Aevi. Cela fait plus de vingt ans que J.Berlioz publie régulièrement des travaux consacrés à cet auteur ou à certains des récits exemplaires contenus dans la somme que ce dernier a réalisée, à tel point qu'il est difficile désormais de penser l'un sans l'autre. On lui doit ainsi la moitié des études sur Étienne de Bourbon répertoriées dans la bibliographie de cette édition. Mais ce n'est pas la seule raison. Dominicain et inquisiteur mort en 1256, Étienne de Bourbon est en effet l'auteur du recueil d'exempla le plus important du XIII ${ }^{\mathrm{e}}$ siècle, le Tractatus de diversis materiis predicabilibus. Cet ouvrage avait déjà retenu l'attention d'A. Lecoy de la Marche, qui en avait publié en 1877 un ensemble d'environ 500 exempla ${ }^{5}$ et, en 1888, une traduction partielle ${ }^{6}$. Mais on en était resté là. Il faut avouer que l'ampleur de ce traité a de quoi effrayer les chercheurs et les éditeurs éventuels. Il comprend en effet plus de 3000 récits, exempla et comparaisons confondus, associés à des arguments doctrinaux (rationes) et à des citations d'auctoritates tirés de la Bible et des Pères de l'Église. L'ensemble est ordonné en cinq parties, auxquelles devaient s'ajouter deux autres parties qui n'ont pu être réalisées, le tout devant correspondre aux sept dons du SaintEsprit. C'est au premier de ces sept dons, le De Dono timoris, qu'est consacré ce premier volume. Il est lui-même divisé en dix chapitres (soit les sept espèces de crainte de Dieu, les effets de la crainte, les raisons de craindre Dieu, la crainte de l'enfer, la crainte du purgatoire, la crainte du jugement dernier, la crainte de la mort, la crainte du péché, la 
crainte des périls présents et enfin celle des ennemis du genre humain, c'est-à-dire le diable). Ce recueil s'ouvre sur un important prologue (publié en tête de cette édition) ${ }^{7}$. Étienne de Bourbon y explique notamment qu'il a rassemblé ces récits (qu'il a empruntés à diverses sources : à des recueils d'exempla antérieurs, à des informateurs qu'il ne manque pas de citer pour légitimer leurs témoignages, ou qu'il a tirés de son souvenir personnel) afin de permettre aux prédicateurs (à qui cet ouvrage est destiné) de trouver rapidement les exempla correspondant au sujet de leurs sermons. Leur insertion doit favoriser l'édification d'un public populaire peu sensible aux subtilités de la théologie et de l'argumentation rationnelle et qui ne saurait être convaincu par la seule énonciation de préceptes moraux.

3 C'est aussi la crainte de Dieu qui est au cœur de l'ouvrage d'Humbert de Romans, $5^{\mathrm{e}}$ Maître général de l'ordre des dominicains et auteur prolifique d'ouvrages sur les règles de discipline que doivent suivre les frères Prêcheurs et sur la prédication. Composé entre 1263 et 1277, date de la mort de cet auteur, le Don de crainte (De dono timoris), appelé aussi Traité de l'abondance des exemples (dont l'édition latine doit paraitre elle aussi dans la collection des Exempla Medii Aevi), s'inspire largement de la première partie du traité d'Étienne de Bourbon. Il lui emprunte en effet les trois-quart des 200 exempla qui s'y trouvent réunis et le même classement en dix chapitres. Les autres récits exemplaires sont tirés de la Vie des Pères, de Jacques de Vitry et, pour un dixième, de sa propre expérience. Là aussi, un important prologue précise les enjeux attribués à ces récits.

4 Tandis que le Traité d'Étienne de Bourbon a été conservé, dans son état le plus complet laissé par son auteur, par cinq manuscrits (ou ensembles de manuscrits), auxquels il faut ajouter cependant les nombreux abrégés qui firent leur apparition à partir du XIV ${ }^{\mathrm{e}}$ siècle, le Don de crainte d'Humbert de Romans a été transmis dans 86 manuscrits. Il a même remplacé la première partie du traité d'Étienne de Bourbon dans certains recueils. Ce succès est, bien sûr, dû à son caractère restreint au regard du traité correspondant de son prédécesseur. Mais il tient aussi au souci de brièveté avec lequel Humbert de Romans réécrit les histoires qu'il emprunte et à son art de la narration (aspect sur lequel il insiste dans son prologue).

Dans la Postface à la traduction de l'ouvrage d'Humbert de Romans, J. Berlioz souligne que celui-ci est confronté à trois enjeux fondamentaux (comme c'est d'ailleurs aussi le cas du traité d'Étienne de Bourbon). Le premier est eschatologique: il s'agit de démontrer l'existence du nouvel au-delà chrétien auquel devront se confronter les futurs morts (qui comprend notamment l'enfer, le purgatoire et le jugement dernier). Le deuxième est ecclésial et consiste à combattre les différentes hérésies. Le troisième est pastoral et concerne plus particulièrement la force rhétorique spécifique de ce "récit bref donné comme véridique et destiné à être inséré dans un discours (en général un sermon) pour convaincre un auditoire par une leçon salutaire », pour citer ici la définition de l'exemplum proposée naguère par J. Le Goff et qui fait désormais autorité8. Comme l'écrit J.-Y. Tilliette, qui renverse en partie cette définition et que cite à ce propos J. Berlioz, l'exemplum médiéval est un « "mode de persuasion qui prend la forme du récit", tout simplement parce que, à l'époque considérée, grâce au développement en littérature de la fonction romanesque, c'est cette forme-là qui est la plus efficace $»^{9}$. Reste à préciser, comme le suggère J. Berlioz, la nature de cette fonction rhétorique et argumentative du récit, à interroger l'efficacité qu'il pouvait 
avoir sur l'auditoire auquel il était adressé et à mesurer du même coup l'impact de cette peur - ou des autres réactions souhaitées - qu'il est censé susciter chez les fidèles.

J. Berlioz achève sa Postface en citant Rutebeuf qui compare les frères Prêcheurs à des pêcheurs et en demandant combien d'auditeurs sont tombés dans les filets tendus par les exempla d'Humbert de Romans et des autres prédicateurs. Le piège du récit ${ }^{10}$ est toujours susceptible en effet d'aliéner celui qui se laisse captiver par son art pour l'enfermer dans un monde de fiction (soit cet au-delà que promet ici le christianisme). C'est la raison pour laquelle Platon avait choisi de chasser Homère et les autres poètes de la cité idéale décrite dans sa République. Aux séductions de la littérature, la philosophie préfère en effet la logique des arguments rationnels. Mais l'homme peut-il pour autant se passer entièrement de mythes et de récits? Les exempla témoignent ainsi, non seulement de l'entreprise de propagande mise en place par l'Église chrétienne et tout particulièrement par les ordres mendiants, mais aussi de la nécessité que semblent éprouver la psyché comme la société humaines de passer par le détour de la narration pour construire son identité et son destin et donner sens à son existence, soit du besoin de s'inscrire dans une temporalité historique et narrative, c'est-à-dire une histoire, que celle-ci soit singulière ou collective, authentique ou fictive.

\section{NOTES}

1. F. C. TUBACH, Index Exemplorum. A Handbook of Medieval Religious Tales, Helsinki, 1969 (Fellow Folklore Communications, 204). À compléter par Les « exempla » médiévaux. Introduction à la recherche, suivie des tables critiques de l'« Index exemplorum » de Frédéric C. Tubach, sous la dir. de J. Berlioz et M. A. Polo de Beaulieu, Carcassonne, 1993.

2. Cf. J. Berlioz, «Les recherches en France sur les exempla médiévaux, 1968-1988 », dans Exempel und Exempelsammlungen, éd. W. Haug et B. Wachinger, Tübingen, 1991, p. 288-317. À noter aussi l'ouvrage pionnier de J.-Th. Welter, L'Exemplum dans la littérature religieuse et didactique du Moyen Âge, Paris-Toulouse, 1927.

3. Cl. Bremond, J. Le Goff et J.-Cl. Schmitt, L'Exemplum, Turnhout, 1982, Typologie des sources du Moyen Âge occidental, 40 ( $2^{\mathrm{e}}$ éd. avec bibliographie mise à jour par J. Berlioz parue en 1996).

4. Pour une présentation des activités de ce Groupe, cf. J. Berlioz et M. A. Polo de Beaulieu, « Le groupe de recherche sur les exempla médiévaux (Paris) », dans Les exempla médiévaux. Nouvelles perspectives, éd. J. Berlioz et M. A. Polo de Beaulieu, Paris, 1998, p. 1-9.

5. A. Lecoy de la Marche, Anecdotes historiques, légendes et apologues, tirés du recueil inédit d'Étienne de Bourbon, dominicain du XIII ${ }^{\mathrm{e}}$ siècle, Paris, 1877.

6. A. Lecoy de la Marche, L'Esprit de noy aïeux. Anecdotes et bons mots tirés des manuscrits du XIII ${ }^{e}$ siècle, Paris, [1888], rééd. sous le titre Le rire du prédicateur. Récits facétieux du Moyen Âge, Textes traduits par A. Lecoy de la Marche, Présentation, notes et annexes par J. Berlioz, Turnhout, 1992 (2 éd. revue et augmentée en 1999). 
7. Sur les prologues des recueils d'exempla, cf. J. Berlioz et A. M. Polo de Beaulieu, « Les prologues des recueils d'exempla ( $\mathrm{XIII}^{\mathrm{e}}-\mathrm{XV}^{\mathrm{e}}$ siècle). Une grille d'analyse », dans La predicazione dei Frati dalla metà del '200 alla fine del '300, Spolète, 1995, p. 268-99, et Id., « Les prologues des recueils d'exempla », dans Les prologues médiévaux, éd. J. Hamesse, Turnhout, 2000, p. 275-321.

8. J. Le Goff, dans Cl. Bremond, J. Le Goff et J.-Cl. Schmitt, L'Exemplum, op. cit., p. 37-38. 9. J.-Y. Tilliette, «L'exemplum rhétorique : questions de définition », dans Les exempla médiévaux. Nouvelles perspectives, op. cit., p. 65.

10. Je fais référence ici au livre de L. Marin, Le récit est un piège, Paris, 1978, dont la première étude, Le pouvoir du récit, est consacrée à la célèbre fable de La Fontaine, Le pouvoir des fables. 